\title{
Establishment of Simultaneous Detection and Quantitation of HCV- RNA by Third Generation Intercalating Dye Real-time PCR
}

Akrahm M. Saleh Habil ${ }^{1}$, Hairul Aini Hamzah ${ }^{1}$, Muhammad Imad Al-Deen Mustafa ${ }^{1}$, Norlelawati A. Talib ${ }^{2}$, Siti Nurul Fazlin Abdul Rahman ${ }^{1}$

${ }^{1}$ Department of Basic Medical Science, Kulliyyah of Medicine, International Islamic University Malaysia

${ }^{2}$ Department of Pathology and Laboratory Medicine, Kulliyyah of Medicine, International Islamic University Malaysia

Presenter: Hairul Aini Hamzah

Introduction: Rapid quantification of hepatitis C virus is helpful in determining and monitoring of the disease progression and nature of the virus replication. The aim of the present study was to establish a fast, specific and sensitive tool for HCVRNA quantification. Materials and Methods: A total of 50 serum samples, comprising of $40 \mathrm{HCV}$-positive and $10 \mathrm{HCV}$-negative, were included in our study. RNA was extracted, reverse transcribed, and then subjected to real-time PCR amplification. Real-time PCR using EvaGreen dye and primers targeting a 5'UTR was carried out. Reference samples with known viral load were treated similarly to the unknown samples and used to create the standard curves. Results: Our method showed a high level of analytical specificity and accuracy, with a low limit of detection $(\sim 2 \mathrm{IU} / \mathrm{ml})$. It yielded repeatable results with less than $4 \%$ of intra- assay variation. The assay covered a broad dynamic range of quantification, ranging from 0.34 to $6 \mathrm{log} \mathrm{IU} / \mathrm{ml}$. The diagnostic sensitivity, specificity, and accuracy were all $100 \%$, indicating neither false positive nor false negative results were obtained. Conclusion: The developed real time PCR using EvaGreen dye has demonstrated a highly analytical and diagnostic performance for HCV quantification, suggesting its potential in clinical diagnosis and management. 